\title{
Performance of cylindrical solar still with hemispherical cover: CFD simulation study
}

\author{
Qahtan A Abed ${ }^{1,}$, Dhafer M Hachim ${ }^{2}$, and Wisam A Abd Al-Wahid ${ }^{2}$ \\ ${ }^{1}$ Technical Institute/ Al-Rumaitha, Al - Furat Al- Awsat Technical University, 31001, Iraq \\ ${ }^{2}$ Engineering technical college/ Najaf, Al - Furat Al- Awsat Technical University, 31001, Iraq
}

\begin{abstract}
Solar distillation collectors are the device that runs on freshwater products. The solar still is one solar thermal technology for purification of water. This technique is employed to convert saline water into freshwater. At this time, the human being increased freshwater required consumption because of the increasing population density. The thermal analysis of a new design of cylindrical solar still (CSS) with hemispherical cover has been studied. A computer simulation model was improved to investigate its performance. The $2 \mathrm{D}$ symmetry simulation models of cylindrical solar still have been validated. The simulation model can emulate the temperature value of different points inside the CSS. The simulation results confirm an acceptable agreement with the experimental result was reported in the literature. From this simulation, it was noted that the freshwater product from the cylindrical solar still obtains the maximum daily productivity of $6.1 \mathrm{~kg} / \mathrm{m}^{2}$ as compared to a traditional single slope solar still SSS as $3.18 \mathrm{~kg} / \mathrm{m}^{2}$ during the day.
\end{abstract}

\section{Introduction}

Renewable energy, especially solar energy, can be used to desalinate the saltwater by found the heat energy needed to carry out the evaporating and condensing process (phase change processes). There are two types of solar desalination processes, direct and indirect processes. In the first type of solar desalination processes (direct), the solar irradiance is received by the collector and converted into thermal energy to evaporate the saltwater. Whereas the second type (indirect system) used the dual separate systems, it combines solar collectors with conventional desalination systems. The lack of drinking water has long been linked with people who live in remote areas. Many people in rural areas of the world spend a large portion of their day getting the freshwater. The freshwater production process that consumes a lot of energy therefore, attempts have been done to improve the solar radiation for operating desalination process by various solar systems [1]. For the time being, various techniques are used to generate drinkable water from polluted water. There are a lot of previous studies of enhancing the desalination proses. Abu-Hijleh and Rababah [2] proposed new way to improve the solar desalination presses throw adding sponge cubes on the tope of water basin surface. This method increases the production of the freshwater

* Corresponding author: qahtan.abed@atu.edu.iq 
from the solar still, it achieved more than 18\% compared with single slope solar still without sponge cubes. There are many other studies in which applications of solar distillation have been conducted on the solar still collectors [3-6]. The freshwater production from any solar still types are increases with increase the water pressure saturation [7]. A theoretical model of steady-state heat transfer for tubular solar still type had been investigated by [8]. The results of FUKUHARA concluded that the suggested model could accurately predict the fresh water output of the solar still. Effects of many factors such as temperatures difference of glass, water vapour and water basin surface, depth of saltwater and glass cover slop etc. on solar still productivity are showed in [9].

Providing people with safe drinking water is getting the government's attention. Therefor many researchers have been doing to improve the productivity of solar distillation technology [10]. Many studies have been applied to improve the efficiency of solar stills collectors, through enhancing the solar still design [11]. The effects of the tilt angle of the glass cover and saltwater depth in the solar still basin on the distillation performance had been studied by [12]. The best daily freshwater productivity from the collector was with the tilt angle of the glass equal to the value of the latitude angle of the setup place. Also, it has been found that solar still productivity during the day decreases with higher saltwater depth.

To enhance the performance of different types of solar still, many previous researchers has been suggested coupling of a conventional solar still collector with flat plate solar collector [13-15]. A comprehensive review of the various types of solar desalination is provided by [16]. They are compared two solar stills models, the tubular type and triangular type. A unique study was done by [17] in a cylindrical solar distillation type. In this case, discrimination is done between the basic single slope solar still with new cylindrical solar still at the same basin area. They carried experiments to test the systems on the summer and winter days. Their conclusions indicated a 3\% increase in the thermal efficiency of the cylindrical type. Nidal et al. [18] have presented a thermal analysis of the performance of a cylindrical solar collector with a curved absorber tube. It was noticed an enhanced heat absorption in the cylindrical solar collectors.

Reviews of the previous researcher show that a large number of experimental studies on a solar still. There are not enough previews studied done on cylindrical solar stills. Therefore, our goal of this simulation is to present a simple solar still building at a low price and can be operated by any person in the population.

Exactly the contrary, there is little numerical study. Therefore to cover this gap with the goal of reducing spent time and increase the accuracy of the results, a transient simulation model was applied in this simulation work. The main objective of this article is to create a numerical simulation model for the study of heat and mass transfer in cylindrical solar still. Presenting the varying temperatures and freshwater product during the day depending on real weather conditions. Also, Investigation the impacts of weather conditions and design to enhance the efficiency of cylindrical solar still.

\section{Description of solar system}

In order to investigate the performance of the TSS, a two-dimensional symmetry simulation model is improved using COMSOL multiphysics 5.4. Fig. 1 shows the suggested cylindrical solar still (CSS) system consists of transparent glass in a cylinder shape with $30 \mathrm{~cm}$ length, $15 \mathrm{~cm}$ diameter and has $0.4 \mathrm{~cm}$ thickness. A coper trough with dimensions $13 \times 2 \times 0.8 \mathrm{~cm}$ was employed as a water basin to keep the saltwater. All sides of the trough are coated with an anti-corrosion paint, as well as it's coated with black paint to increase its absorptivity. To maintain a constant level of saltwater in the trough during day, a feed water tank is preparing for CSS. The model in all its dimensions was used in the previous experimental study by [17]. 


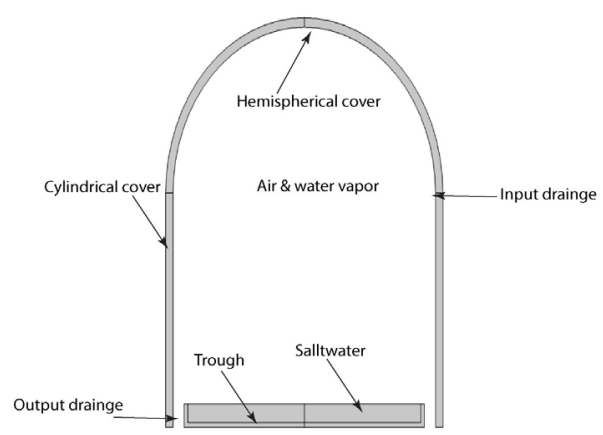

Fig.1. Schematic diagram of cylindrical solar still

\section{CFD COMSOL Modeling}

\subsection{Create the geometry of CSS}

Cylindrical solar still (CSS) is an uncomplicated solar desalination project, as it is employed to convert saline water to fresh water. The improved CSS used for the existing study consists of a transparent cover shaped of vertical tubular with hemispherical and a black water basin. A 2D symmetry geometry is applied for simulations in the current work. The geometry of the cylindrical solar still (CSS) has been modelled by COMSOL Metaphysics as CFD simulation software program. The two dimensions symmetry geometry of cylindrical solar still illustrates in figure 2. The geometric model of the cylindrical solar still consists of a hemispherical cover on the upper sided, a transparent cylindrical case on the front side and a black rectangular water basin containing salt water.

The solar radiation incident on the cylindrical cover surface, part of its path through it, and other parts are reflected to the sky. The basin is worked to absorb the solar irradiance, and the temperature will start to increase. The absorbed heat energy is transferred to the saltwater to increase its temperature. From the surface of saltwater there are three kinds of heat transfers processes which are radiative heat transfer $\left(\mathrm{Q}_{\mathrm{r}, \mathrm{w} \mathrm{g}}\right)$, convective heat transfer $\left(\mathrm{Q}_{\mathrm{c}, \mathrm{w} \mathrm{g}}\right)$ and evaporative heat transfer $\left(\mathrm{Q}_{\mathrm{e}, \mathrm{w}_{\mathrm{g}}}\right)$ (see figure 2$)$. The saturator vapour is accumulated up the water surface. Which begins to condense on the inner side of the cylinder cover after losing its latent heat. The drops of freshwater are falling below by gravity and it is accumulated in a freshwater tank. The number of drops of freshwater is increasing as the temperature differences between the saltwater temperature and the cylinder surface temperature increase. There are two types of heat transfers from cylinder cover to ambient, which is convective $\left(\mathrm{Q}_{\mathrm{c}, \mathrm{g}_{\mathrm{a}} \mathrm{a}}\right)$ and radiation $\left(\mathrm{Q}_{\mathrm{r}, \mathrm{g}_{\_} \mathrm{a}}\right)$ as losses. Other type of heat losses from the basin by convection to ambient $\left(\mathrm{Q}_{\mathrm{l}, \mathrm{b} \_\mathrm{a}}\right)$. 


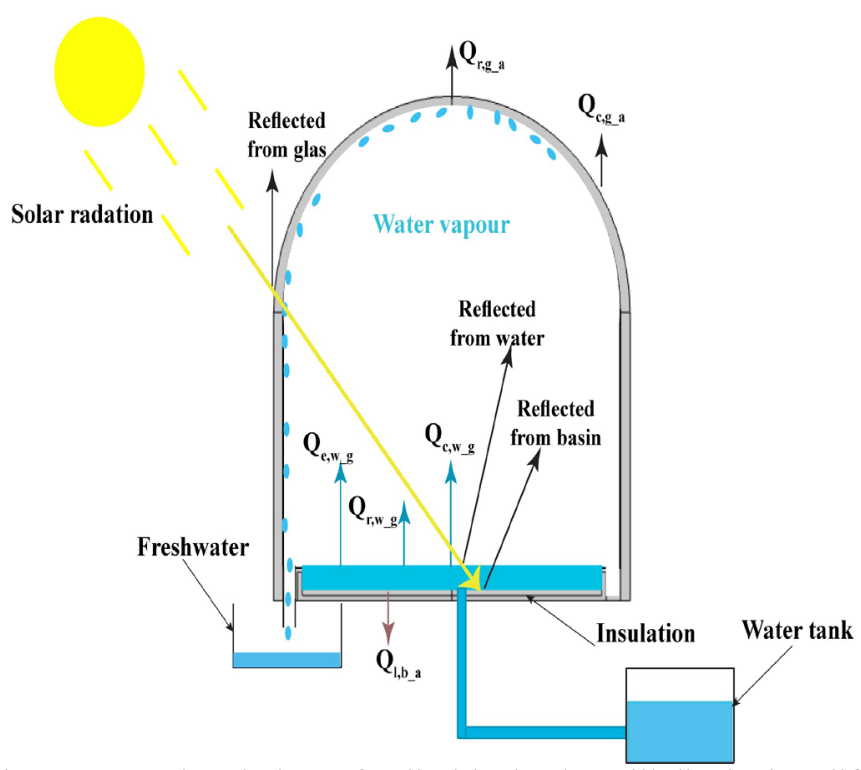

Fig. 2. The cross-sectional view of cylindrical solar still displaying different losses and gain heat

\subsection{The model mesh}

The two-dimension CSS Geometry (2D), properties and functions were defined in COMSOL Multi-Physics. Also the CSS grid has been created by COMSOL Multi-Physics. Given the difficult computational domain and the many intersections surface, the CSS is separated into different parts, which are divided by the mesh, and a system is applied to combine the meshes between all parts. To achieve accurate simulation results, the fine element size for the grid has been used. The 2D symmetry simulation model of cylindrical solar still with a grid is presented in figure 3. The geometry mesh was built from lots of small mesh elements. Which consists of 1500000 elements. The mesh independence test was performed to test the grid size of the simulation model. The mass transfer and heat energy were analysed in this simulation.

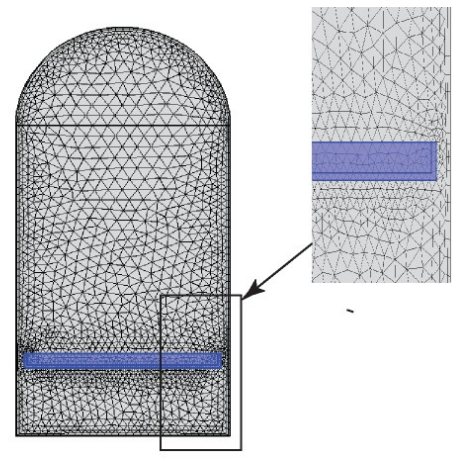

Fig. 3. Grid created at the CSS with different numbers of elements 


\subsection{Main governing equations}

The mixture of air and vapour movement inside the cylindrical solar stills is decided to be a laminar flow moving according to the buoyancy force. The fluid in any state must be appropriate with the scent law of thermodynamics (conservation of mass) [19].

\subsubsection{Continuity equation}

$$
\frac{\partial \rho}{\partial t}+\nabla \cdot(\rho \overrightarrow{\bar{v}})=0
$$

Where $\vec{v}$ and $\rho$ are the velocity vector and density, respectively.

\subsubsection{Momentum equation}

Convection heat transfer increase in the CSS as the temperature difference between the saltwater surface and the hemispherical cover surface. The momentum equation for two cases is expressed below:

For gas (mixture of air-water vapour)

$$
\frac{\partial}{\partial t}(\rho \overrightarrow{\bar{v}})+\nabla \cdot(\rho \overrightarrow{\bar{v}} \overrightarrow{\bar{v}})=-\nabla \cdot(\bar{p})+\nabla \cdot\left(\vec{\tau}_{e f f}\right)+\rho \vec{g}
$$

For liquide (water)

$$
\frac{\partial}{\partial t}(\rho \overrightarrow{\bar{v}})+\nabla \cdot(\rho \overrightarrow{\bar{v}} \overrightarrow{\bar{v}})=-\nabla \cdot(\bar{p})+\nabla \cdot\left(\vec{\tau}_{e f f}\right)+\rho \vec{g}
$$

where: $\vec{\tau}_{\text {eff }}$ shear stress effective, $\beta$ thermal expansion coefficient (water)

\subsubsection{Energy equations}

The temperatures variation is achieved by solving the following energy equation in various parts of the CSS is expressed:

$$
\frac{\partial}{\partial t}(\rho \bar{E})+\nabla \cdot(\overrightarrow{\bar{v}}(\rho \bar{E}+\bar{p}))=\nabla \cdot\left(\lambda_{e f f} \nabla \bar{T}-\sum_{j} \bar{h}_{E . j} \overrightarrow{\vec{J}}_{j}\right)+S_{h}+S_{L}
$$

For liquide (water)

For solid (glass)

$$
\frac{\partial}{\partial t}(\rho E)+\nabla \cdot(\vec{v}(\rho E+p))=\nabla \cdot(\lambda \nabla T)+S_{h}+S_{L}
$$

$$
\frac{\partial}{\partial t}(\rho E)=\nabla \cdot(\lambda \nabla T)+S_{h}+S_{L}
$$

Where: $\bar{h}_{E . j}$ and $\vec{J}_{j}$ are the diffusive flux and sensible enthalpy, $\lambda_{\text {eff }}$ thermal conductivity effective, $S_{h}$ is the latent heat of evaporation and $S_{L}$ is the absorbed radiant energy. 


\subsection{The boundary and initial conditions}

There are three physicals used in this simulation: heat transfer in solids, heat transfer in fluid and condensation physics. The solar irradiation is passing through the upper hemispherical cover. Then the transmissivities irradiance falls on the water surface, and absorbed by the water basin.

The governing equations for each of these elements are solved to simulate the system performance. The above governing equations were solved in accordance with expressions and assumptions that have been implemented for this simulation study:

1. The boundary symmetry conditions have been used in the current simulation model of CSS as given in figure 3.

2. Neglected any source for the thermal energy generation inside the solar still.

3. The considered the heat transfer from the top boundary were convection and radiation to the surrounding.

4. Forced heat transfer by convection from the still surface to the ambient was neglected.

5. The influence that the condensed water film has on the solar radiation that enters the collector have been neglected.

6. At the time of sunrise and sunset, the solar still trough was received the solar radiation through the cylinder wall.

7. The system leakages don't occur.

8. The estimated is no slip for all the walls of the cylindrical solar still

The initial temperature of the surrounding and inside the CSS are estimated to be $25^{\circ} \mathrm{C}$ and $30{ }^{\circ} \mathrm{C}$ respectively. Additionally, the velocity was estimated equal to $0 \mathrm{~m} / \mathrm{sec}$ in all initial states. The input data of weather conditions (solar radiation, wind speed and ambient temperature) are used according to the previous experimental work [17]. Fig. 3 presents the variation of solar irradiance and ambient temperature during the day for the CSS.

\subsection{The model validation}

The numerical simulations are performed in the cylindrical solar still. COMSOL multiphysics techniques are utilised to guess the amount of freshwater productivity and temperature distribution of different parts CSS. With the purpose of validating the simulation model, the same weather conditions among the present simulation and the previous experimental work have been implemented [17]. The productivity comparison is presented in fig. 4. It can be observed that the simulation results are very good to agreement with the experimental results. The formula of mean bass error (MBE) is used to show the simulation accuracy as follows:

$$
M B E=\frac{1}{n} \sum_{i=1}^{n}\left(P_{i, \text { simu }}-P_{i, \exp }\right)
$$

where: $P_{i, \text { simu }}$ and $P_{i \text {,exp }}$ are the simulation and experimental productivity, respectively, while $n$ referring to the total number of values. 


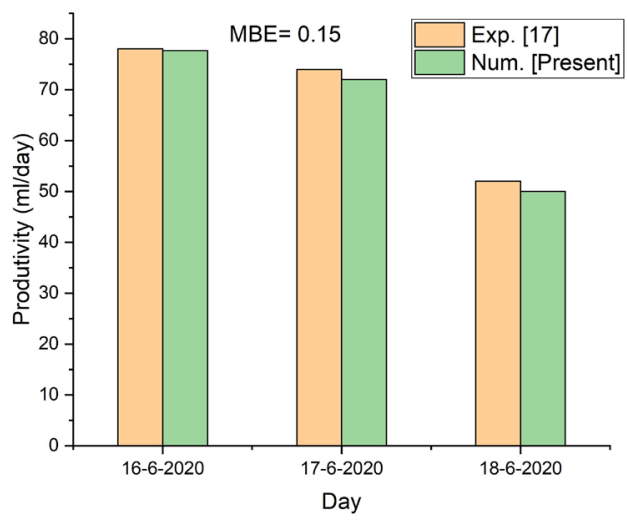

Fig. 4. Comparison of freshwater productivity between the simulation and experimental results

\section{Results of the simulation}

The CFD numerical simulations were performed by the COMSOL multiphysics program. The solar irradiance and surrounding air temperatures were measured during the experimental test (on Najaf- Iraq, latitude $32^{\circ} 02^{\prime}$, longitude $44^{\circ} 20^{\prime}$ ) have been plotted in figure 5. The meteorological data of weather have been selected based on the experimental test, and different five weather conditions days were used in the simulation (see figure 5). It presents the variations in ambient temperatures and solar irradiance during the day. This figure shows an hourly variation of solar irradiance and ambient air temperature for different days (22-5-2019, 3-10-2019, 30-12-2019, 18-2-2020 and 16-6-2020).

At the start of all days, the amount of solar irradiance was limited. After that, it's increasing to be the maximum value in the middle of the day, and then these values are returning to decrease. The air surrounding temperature (ambient) was the maximum value on 16-6-2020 compared with other days.

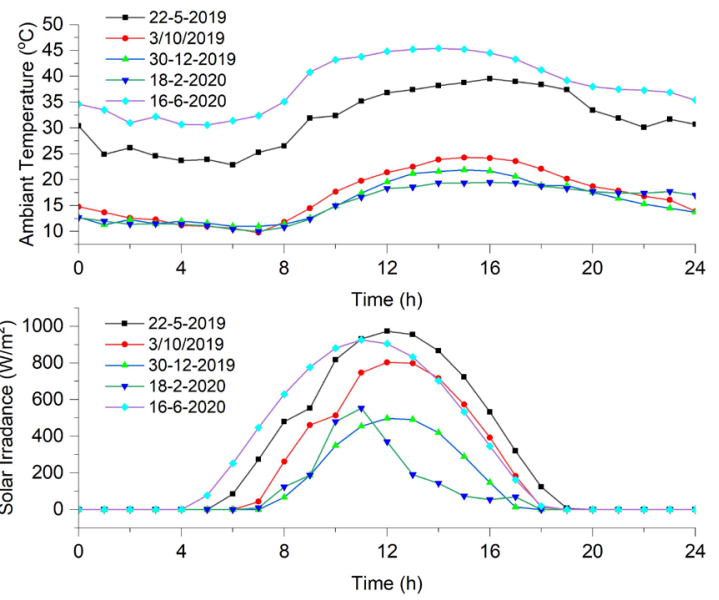

Fig. 5. Variation of the intensity of solar irradiance and ambient temperature during the day. 
In this investigation, the CSS designed was simulated to show the influence of this new designed on the freshwater productivity. The contours of variation temperature on the front side of the CSS during the different hours of the day has been illustrated in figure 6. It shows the difference in temperature between on the cover saltwater surface. When this is increased, the productivity of freshwater will increase. Nevertheless, the difference in temperatures decreases about $15{ }^{\circ} \mathrm{C}$ at the time of $12 \mathrm{PM}$ and $6 \mathrm{AM}$, which leads to decrease freshwater protect during the night.
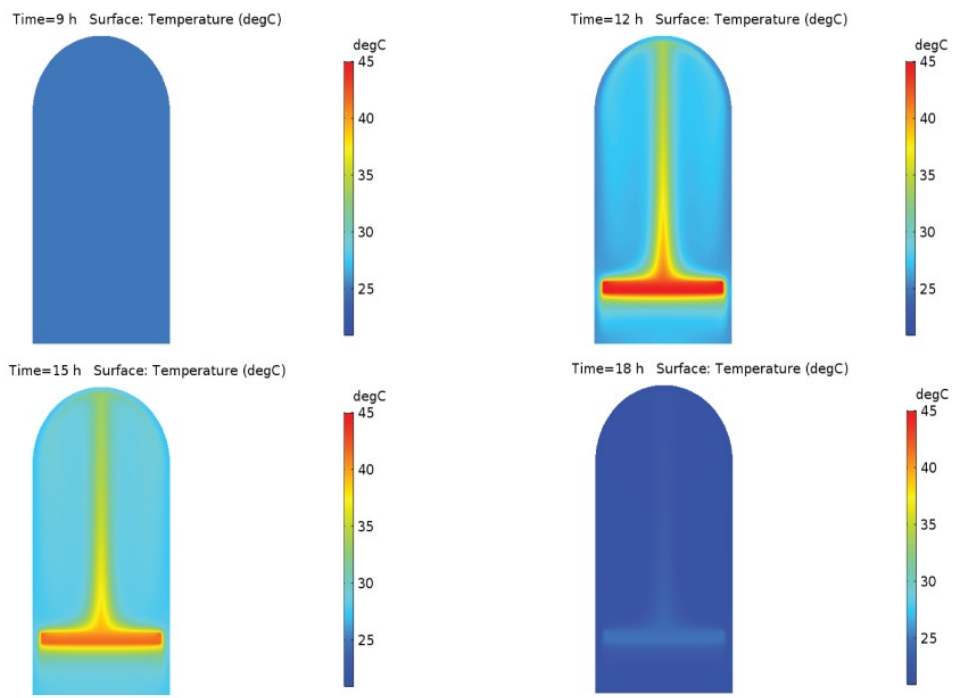

Fig. 6. Variation of the temperature contours of the CSS during a day at (a) 9AM (b) 12PM (c) 15PM (d) 18PM.

The contour of the various pressure on the symmetry cylindrical solar still is displayed in Fig. 7A. The non-uniform pressure distribution was seen for the inside of the symmetry plan CSS. The result showed there is an increase in vapour pressure in the upstream flow direction. A side view of velocity contours in running water vapour and air inside the CSS is shown in figure 7B. In the CSS there are no restrictions, so the evaporated water is moving up to stick to the cold glass surface and then dropped to exits out of the CSS.

Time $=15 \mathrm{~h}$ Contour: Pressure $(\mathrm{Pa})$ Surface: 1 (1)

(A)

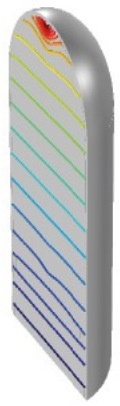

$\mathrm{Pa}$
$\times 10^{-3}$

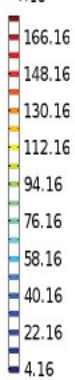

Time $=12 \mathrm{~h}$ Contour: Velocity magnitude $(\mathrm{m} / \mathrm{s})$ Surface: 1 (1)

(B)

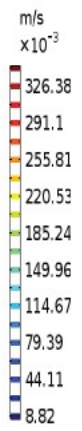

Fig. 7. (A) The static pressure contours for the optimized CSS model, (B) The vapour velocity contours inside the CSS model. 
New simulation model for a conventional single slope solar (SSS) still have been developed to 0comparison with CSS. It is observed that the solar radiation incident during the day on the glass cover of SSS is less than it on the CSS. Due to geometry of solar still, it allows receiving the solar radiation at the front side of the SSS, while the CSS receives the solar radiation in all direction. The comparison results are illustrated in Figure 8. It shows that the fresh water product from of the present model CSS with hemispherical was higher than it in SSS.

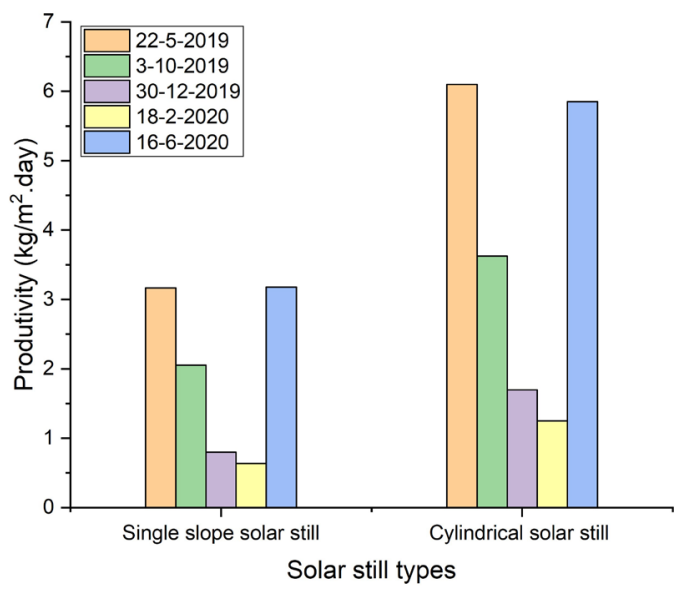

Fig. 8. Comparison of the hourly production for single slope solar still and cylindrical solar still.

\section{Conclusion}

Cylindrical solar still was successfully designed by using COMSOL multiphysics and the simulations were performed. The $2 \mathrm{D}$ with 2 phase simulation model was built. The simulation model was implemented for the water vapor mixture. The incident solar radiation was waking to vaporize the saltwater and the CSS was ready to display condensed water vapor accumulates on the inside glass surface. Also, this new design allows visible freshwater drops that drop down to the fresh water tank. Proposed new geometry of the cylindrical solar still in this study acceptable fresh water yield in compare with conventional single slope solar still. The daily fresh ware product was maximum with CSS and found as $6.1 \mathrm{~kg} / \mathrm{m}^{2}$, while from the traditional SSS is found as $3.18 \mathrm{~kg} / \mathrm{m}^{2}$. The maximum deviations between previous experimental and the present simulation results are found as 0.15 . 


\section{References}

1. A. Mahmoud, H. Fath, S. Ookwara, and M. Ahmed, Desalination 467, 29 (2019)

2. B. A. Abu-Hijleh, Energy Conversion and Management 44, 1411 (2003)

3. M. A. Sharaf, Journal of Solar Energy Engineering, Transactions of the ASME 134, (2012)

4. S. Abdallah and O. O. Badran, Desalination 220, 669 (2008)

5. A. S. Nafey, M. Abdelkader, A. Abdelmotalip, and A. A. Mabrouk, Energy Conversion and Management 43, 937 (2002)

6. V. Velmurugan, S. Senthil Kumaran, V. Niranjan Prabhu, and K. Srithar, Thermal Science 12, 153 (2008)

7. F. Muñoz, E. Barrera, A. Ruiz, E. M. Martínez, and N. Chargoy, Desalination 476, $114241(2020)$

8. A. Ahsan and T. Fukuhara, Solar Energy 84, 1147 (2010)

9. V. Velmurugan and K. Srithar, Renewable and Sustainable Energy Reviews 15, $1294(2011)$

10. V. S. Vigneswaran, G. Kumaresan, B. V. Dinakar, K. K. Kamal, and R. Velraj, Journal of Energy Storage 26, 101019 (2019)

11. S. Al-Kharabsheh and D. Y. Goswami, Desalination 156, 323 (2003)

12. H. Ş. Aybar and H. Assefi, Desalination and Water Treatment 37 (2012)

13. R. S. Subramanian, G. Kumaresan, R. Ajith, U. Sabarivasan, K. K. Gowthamaan, and S. Anudeep, Materials Today: Proceedings (2020)

14. A. a. Badran, A. a. Al-Hallaq, I. a. Eyal Salman, and M. Z. Odat, Desalination 172, 227 (2005)

15. O. O. Badran and H. A. Al-Tahaineh, Desalination 183, 137 (2005)

16. H. Ş. Aybar and H. Assefi, Desalination and Water Treatment 7, 35 (2009)

17. M. A. Al -Amir Khadim, W. A. A. Al-Wahid, D. M. Hachim, and K. Sopian, Smart Science 1 (2021)

18. N. H. Abu-Hamdeh, R. A. R. Bantan, M. Khoshvaght-Aliabadi, and A. Alimoradi, Renewable Energy 161, 1260 (2020)

19. COMSOL Multiphysics 5.4 Documentation (2020) 